to carry out spectrophotometry on such material much more accurately and with much more concentrated suspensions than hitherto, and the state of pigments, enzymes, etc., in living animal and plant cells and micro-organisms can be investigated. Results obtained by this method will be reported in detail by one of us (R. B.).

(7) Combination of refractometry and mass determination. By means of interference microseopy it is possible to determine the product of refractive index and thickness, and hence the dry mass of a living cell ${ }^{15,9}$. Although refractometry and mass determination are closely related, the information given by the former, that is, the concentration of solids, is generally more fundamental. Thus the knowledge of the actual mass of a structure like an amobal pseudopodium is of no great interest, because it depends on the size of the pseudopodium, which may be varying rapidly. The local concentration of solids is of much greater value. When the two methods are combined, however, it is possible in principle to obtain a considerable amount of useful information about living cells. If the product of refractive index difference and thickness and the refractive index itself are measured, the thickness can be calculated. The integrated product of thickness and projected cell area then gives the cell volume. Thus, from two optical measurements it is possible to derive (1) the dry mass of part or the whole of a cell, (2) the concentration of solids in different parts of the cell, (3) the cell thickness, (4) the cell volume, (5) the concentration of water in different regions, (6) the total mass of water. Such facts provide a useful basis for much quantitative work on living cells.

This work was made possible by grants for apparatus from the Royal Society and the Rockefeller Foundation. Generous assistance was also provided by the Nuffield Foundation and the Smith, Kline and French Foundation.

${ }^{1}$ Vlds, F., C.R. Soc. Biol., Paris, 85, 492 (1921).

${ }^{2}$ von Angerer, K., Arch. Hyg., Berl., 93, 14 (1923).

s Faure-Fremiet, E., Protoplasma, 6, 521 (1929). Frederikse, A. M., Protoplasma, 19, 473 (1933). Pfeiffer, H. H., Z. wiss. Mikr., 48, 47 (1931); Protoplasma, 30, 321, 334 (1938).

4 Barer, R., and Ross, K. F. A., J. Physiol., 118, 38 P (1952).

'Zernike, F., Physica, 9, 686, 974 (1942)

- Dyson, J., Proc. Roy. Soc., A, 204, 170 (1950).

TTennent, H. G.. and Vilbrandt, C. F., J. Amer. Chem. Soc., 65, 424 $(1943)$.

- Cecil, R., personal communication (1951).

- Lavies, H. G., and Wilkins, M. H. F., Nature, 169, 541 (1952).

${ }^{10}$ Crawford, G. N. C., and Barer, R., Quart. J. Micro. Sci., 92, 403 $(1951)$, and in the press.

"Ponder, E., "Hemolysis and Related Phenomena" (London: J. and A. Churchill, 1948)

${ }^{12}$ Crossmon, G. C., Stain Technol., 24, 241 (1949).

"3 Barer, R., Nature, 167, 642 (1951) ; "Contraste de Phase et Contraste par Interférences" (Paris : Rev. d'Optique, 1952).

14 Barer, R., J. Physiol., 119, Proceedings Dec. (1952).

16 Barer, R., Nature, 169, 366；170, 29 (1952).

\section{FLAVOUR ASSESSMENT}

A

SYMPOSIUM on flavour assessment, in which

the Food Group of the Society of Chemical Industry, the Biological Methods Group of the Society of Public Analysts and the Biometric Society joined, was held on the afternoon and evening of Wednesday, March 11, at the Wellcome Research Foundation, Euston Road, London. The chairman of the Food Group, Prof. H. D. Kay, took the chair at the afternoon session, and Dr. H. O. J. Collier, of the Society of Public Analysts, and Dr. Katherine
Coward, of the Biometric Society, at the after-tea and evening sessions. Some two hundred and thirty people were present.

The first speaker was Dr. E. D. Adrian, who discussed the physiological background of flavour assessment. He pointed out that while the strict physiology of the sense-organs tells us little about the sensations experienced by the individual, which are elaborate constructions of the central nervous system, the physiologist can tell us a good deal about the kind of information which comes in when the end organs are stimulated. The concept presented to consciousness is an edited synthesis of this information; in the case of our appreciation of food and drink, it depends both on the signals coming from the eyes as well as the nose and mouth, and also on the idiosyncratic likes and dislikes acquired during our upbringing and past experience. The physiologist deals with the stage where the environmental change is analysed by the sense organs; he can measure the size, number, grouping and spacing of the brief impulses travelling up the sensory nerve fibres.

The flavour of food is signalled by the taste buds in the tongue and the back of the mouth and the large olfactory organ at the back of the nose. In man, the olfactory organ, which has an area of about $2 \mathrm{sq}$. cm. on either side, contains several million long, sensory cells, each ending in a hair-like process which projects into the surface layer of mucus and water on the surface of the organ.

With smells, there has always been the difficulty of making any classification or analysis of the qualitative aspects, or of producing a scale of smells. Recent research has left the sensation out of account and recorded the signals which the sense organ sends to the brain. Experiments have been carried out with the rabbit, which has a large olfactory organ, to determine the character of the impulses - changes in electrical potential-passing along the olfactory nerve after a measured stimulus, consisting of a definite quantity of the vapour of a chemical substance of known composition, has been brought to the olfactory surface within a definite and fairly short time. Dr. Adrian showed a number of slides recording these impulses.

With a similar stimulus, the time course of the discharge of impulses is characteristic, and may help the animal to distinguish one smell from another. The esters and substances soluble in water seem to act more rapidly than those only soluble in lipoids. It is possible that there may be different types of reception, perhaps depending on the distance of the cell nucleus in the long sensory cell from the receptor hairs. Thus air which has passed over coffee gives a group of potential spikes on the record of the discharge differing from that given by air which has passed over tea. When pure chemical substances are tried, there seems to be at least four classes of substances of which the discharge patterns can be distinguished. This is most obvious when the stimulus is not too far from the threshold, that is, when only a few conducting units are in action.

How the stimulating molecules of the odoriferous substances excite the end organs is a different problem; but at least we know that the olfactory organ sends the same sort of messages into the brain as the other sense organs, and that judgments of flavour are based on a central editing and synthesis of signals arriving via a fairly large number of afferent channels. 
Mr. H. G. Harvey (British Food Manufacturing Industries Research Association) dealt with certain basic considerations in regard to flavour assessment from a somewhat different angle. In the well-fed human, the reaction to flavour is still primitive and largely confined to like or dislike, or preference of one food to another, though many separate sensory messages associated with colour, temperature, texture, taste, odour, obviously enter into any such judgment. Mr. Harvey emphasized the importance of visual appearance, quoting Moir's experiment where table jellies with colours not conforming to the flavours customarily associated with these colours were tasted by a large group of people, most of whom failed to allocate the flavours correctly. When food intended for sale to persons of normal vision is being tested for flavour, the normal association of colour and flavour should be allowed to operate.

Nearly every type of tasting test, Mr. Harvey pointed out, falls into one of two categories: (1) consumer preference and (2) grading, though the way in which particular assessments are made varies widely. A sound statistical planning is necessary, whatever method is used. Mr. Harvey compared, with examples, the 'paired comparison' method and the 'triangular' test, where three samples, of which two are identical, are presented to each assessor. $\mathrm{He}$ considered that assessors should, where possible, be given the simplest possible judgment to make. Assessors vary greatly in their discrimination for reasons that are usually obscure, though nonsmokers do not seem to show any significant difference in tasting ability from smokers.

Mr. A. S. C. Ehrenberg (Institute of Psychiatry, Maudsley Hospital, London) and Dr. J. M. Shewan (Torry Research Station, Aberdeen), in a paper on the objective approach to sensory tests, illustrated their conclusions from a study of present-day methods of preserving fish in palatable form, using carefully trained taste panels for the assessment of qualities which go a little beyond simple flavour. They endeavour to measure 'eating quality', grading this variable on a ten-point scale, each point of which is given a detailed description. The panel is trained to agree on the association of the descriptive terms and the place on the scale. A major difficulty is to decide whether or not the level of assessment remains reasonably constant over a period of time; quickfrozen fish stored at low temperatures show little change over months of storage and have some value as standards ; also, objective chemical measurements (total volatile bases) seem to agree fairly consistently with the position on the 'eating quality' scale given by the organoleptic assessments.

Mr. J. M. Harries (Ministry of Food) also spoke on specialist grading tests and consumer acceptance trials. The consumer acceptance or preference tests, the results of which vary with standards of living, have usually a wide scatter of individual results about an average. When attempting to forecast consumer preference, the scatter is as important as the average. The relation of this variation to the economic concept of elasticity of demand was discussed. In consumer preference tests, the food should be presented in the form in which it is normally used. One method employed is to offer five samples, three (identical) of one kind, two (identical) of another-a method useful in assessing the effect of alternative treatments on the flavour of a given food.

For specialist grading tests, a limited panel of individuals of trained acuity is used; such tests are not concerned primarily with likes and dislikes but are meant to effect a sensory analysis of flavour or other food characteristics, previously formulated in as precise a way as possible, and discussed beforehand by the panel. By such means, it is often possible to place different samples in a consistent order, or on a numerical scale. Mr. Harries reviewed some of the statistical methods of dealing with the test data.

Dr. J. O. Irwin (London School of Hygiene and Tropical Medicine) gave an interesting statement of the biometrician's point of view. There has been in the past a good deal of doubt as to the legitimacy of speaking of the measurement of sensation, and whether the only measurable quantities are the stimuli that evoke the sensation. His view is that the attempt to provide and classify such measurements has, nevertheless, to be made. He referred to the classification proposed by Chambers into (1) nominal, (2) ordinal, (3) interval and (4) ratio scales, and briefly described the use and limitations of each of these scales. The pragmatic approach to ordinal scales, not infrequently used in flavour assessment, is often better than a too pedantic use of a precise form of metric - an example was given of this from results on bacterial plate counts of milk. The biometric assessment of the properties of food, such as odour or flavour, is a type of assay not too dissimilar from, say, the biological assay of the amount of insulin in a given preparation.

Dr. Irwin directed attention to a valuable publication by the U.S. Department of Agriculture, namely, Bulletin No. 34 of the Bureau of Human Nutrition and Home Economics, 1950, in which a thorough examination of many aspects of the 'specialist grading' type of test is given. He ended his talk by scrutinizing from the biometric point of view some of the findings mentioned by the previous speakers.

A short discussion followed the conclusion of each of the five papers presented.

\section{OBITUARY \\ Dr. Marc Daniels}

Dr. Marc Daniels, a member of the Tuberculosis Research Unit of the Medical Research Council, died in London on March 3 at the age of forty-six. Educated in Manchester and Paris, he took his British medical qualification in 1937 and, a few years later, entered the public health field. After two years in Lincolnshire, however, he gained a scholarship at the Royal College of Physicians, a committee of which was directing a survey on the epidemiology and prevention of tuberculosis in young adults, under the Prophit Trust. From this point Daniels concentrated upon tuberculosis, and, after outstanding work in this survey during 1942-45, and in the preparation of its important report, which among other beneficial effects led to the official recognition of tuberculosis in nurses, laboratory workers and certain other categories as an industrial disease, he joined UNRRA as a consultant in post-war Europe. Some of his observations in this sphere were recorded in his Milroy Lectures to the Royal College of Physicians in 1949.

In 1946 Daniels joined the staff of the Medical Research Council, and thereafter was responsible for the practical co-ordination of two important lines of 